\title{
Percutaneous balloon valvuloplasty for pulmonary valve stenosis in infants and children
}

\author{
I D SULLIVAN, P J ROBINSON, F J MACARTNEY, J F N TAYLOR, P G REES, \\ C BULL, J E DEANFIELD
}

From the Thoracic Unit, Hospital for Sick Children, London

SUMMARY Pulmonary valve stenosis was relieved by balloon dilatation during cardiac catheterisation on 27 occasions in 23 infants and children aged 7 days to 12 years, median 31 months (three aged $<2$ weeks). Pulmonary valve diameter was estimated by cross sectional echocardiography to assist in the choice of balloon size. Before dilatation the right ventricular systolic pressure ranged from 41 to 190 (median 92) $\mathrm{mm} \mathrm{Hg}$ and was suprasystemic in 10 patients. There were significant reductions in the ratio of right ventricular to systemic systolic pressure and pulmonary systolic pressure gradients immediately after balloon dilatation. Twelve patients underwent recatheterisation (11 at six months and one at one week after balloon dilatation), which showed further improvement with significant reductions in right ventricular pressure or pulmonary valve gradient or both, particularly in the patients with the least satisfactory initial results. This improvement was attributed to resolution of the obstruction at infundibular level. Repeat pulmonary valve dilatation was successfully performed in four patients who had poor results after initial dilatation.

Balloon pulmonary valvotomy appears to provide good short term and medium term relief of pulmonary valve stenosis and may obviate the need for surgery in many cases. An apparently poor immediate haemodynamic result does not preclude a good longer term result.

The relief of pulmonary valve stenosis by balloon dilatation during cardiac catheterisation was first reported in $1982 .^{1}$ Subsequently, the results of this procedure have been reported in series of patients with wide age ranges ( 3 months to 56 years) $)^{2-4}$ and even in a neonate. ${ }^{5}$ Good immediate results were obtained in each of these studies.

Spontaneous regression of residual right ventricular outflow systolic pressure gradients and right ventricular systolic pressure has been reported after surgical pulmonary valvotomy. ${ }^{6}$ This is presumably related to regression of right ventricular infundibular hypertrophy. A similar phenomenon has not previously been reported after balloon dilatation of the pulmonary valve in children.

The aim of this study was to determine which

Requests for reprints to Dr I D Sullivan, Thoracic Unit, The Hospital for Sick Children, Great Ormond Street, London WCIN 3JH.

Accepted for publication 9 July 1985 children from a consecutive series with a wide range in age and severity of pulmonary valve stenosis would respond favourably to balloon dilatation and whether this response would be maintained.

\section{Patients and methods}

The relief of pulmonary valve stenosis by balloon dilatation was attempted on 27 occasions in 23 patients between April 1984 and February 1985. Patients were aged 7 days to 12 years (median 31 months). Three patients were aged $<2$ weeks (Table).

Eight patients with isolated pulmonary valve stenosis were catheterised, but balloon dilatation not performed, during the same period. In three neonates with severe pulmonary valve stenosis satisfactory catheter placement across the pulmonary valve could not be obtained. In three others crossing the stenosed valve with a balloon catheter was not considered prudent. In two patients, investigated early in the series, the peak pressure in the right 
Table Systolic pressures ( $\mathrm{mm} \mathrm{Hg}$ ) at rest, immediately after balloon pulmonary valve dilatation, and at repeat catheterisation

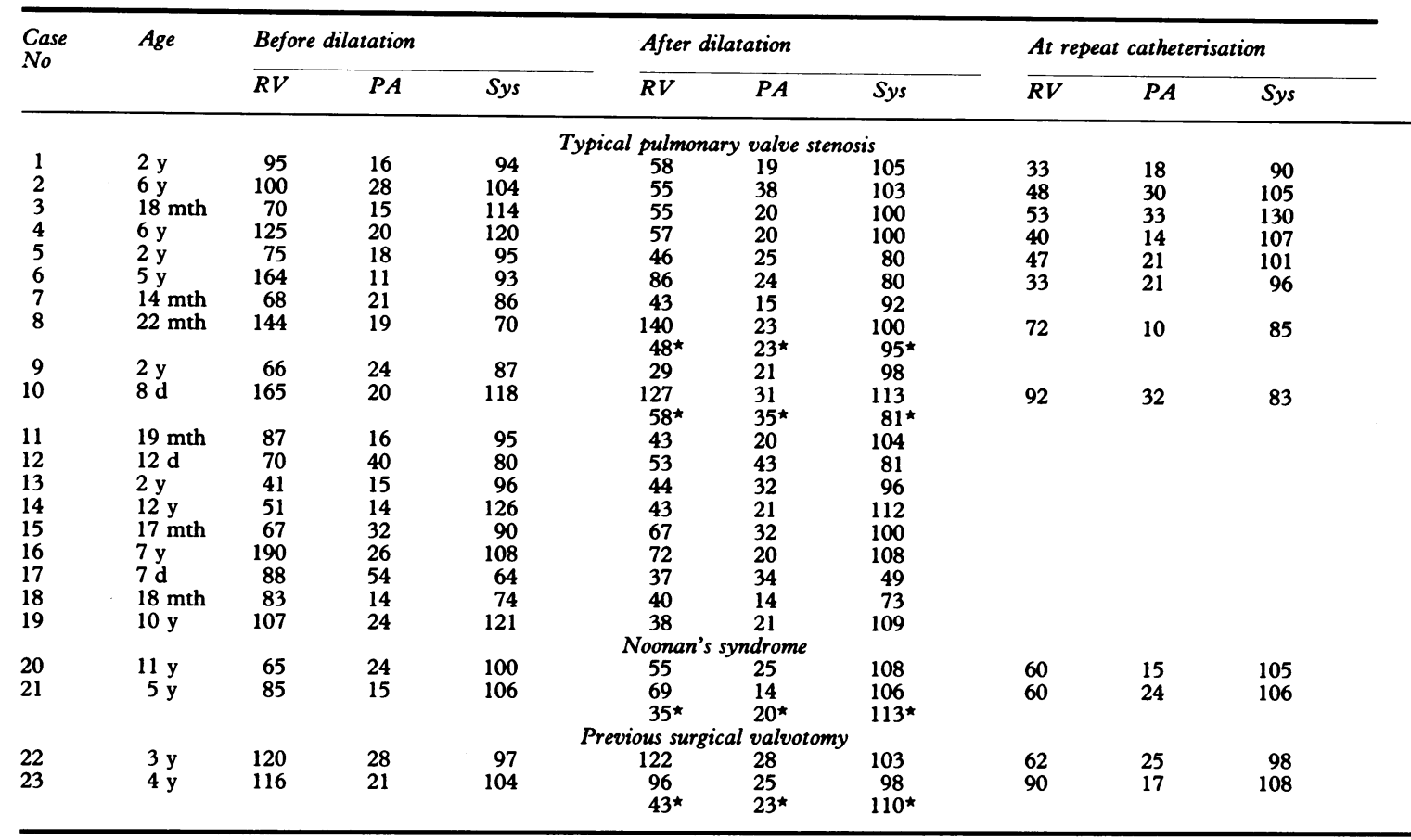

^Pressures after repeat balloon dilatation. PA, pulmonary artery; RV, right ventricle; sys, systemic.

ventricle was twice that in the left ventricle. The third patient had suprasystemic pressure in the right ventricle and had arrested after ventriculography. Surgical valvotomy was performed in these six patients. The severity of pulmonary valve stenosis was insufficient to indicate balloon valvotomy or surgery in an infant weighing $3.5 \mathrm{~kg}$ and in an older child with Noonan's syndrome. Balloon valvotomy was not performed when pulmonary valve stenosis was associated with a large atrial septal defect in two patients as it would not obviate the need for surgery.

\section{INTERNAL CARDIAC MEASUREMENTS}

The diameter of the pulmonary valve ring was estimated by cross sectional echocardiography before catheterisation. Internal dimensions were measured by electronic calipers on video freeze frames, where the origins of the pulmonary valve leaflets could be clearly seen, without specific regard to the phase of the cardiac cycle. Multiple views were used, but short axis parasternal cuts were usually used to determine the choice of balloon size. External balloon diameters that were equal to or slightly less than the measured pulmonary valve ring diameter were selected for the first 14 procedures: balloon diam- eters about $20 \%$ greater than the pulmonary valve ring diameter were used subsequently except in one patient (case 14) (Table), in whom the largest balloon diameter available $(20 \mathrm{~mm})$ was $5 \mathrm{~mm}$ less than the measured pulmonary valve ring diameter.

\section{CARDIAC CATHETERISATION}

Cardiac catheterisation was performed under local anaesthesia usually through a saphenous vein cut down or a femoral vein after percutaneous puncture. A right axillary cut down was used in one patient after multiple previous investigations. Oximetry and haemodynamic measurements were recorded at rest, which always included right ventricular and pulmonary artery pressure, and were followed by right ventricular angiography. Femoral artery cannulation allowed continuous monitoring of the systemic arterial pressure, although this was not performed in the neonatal patients. A balloon catheter (Medi-Tech) of appropriate size was then introduced and positioned across the pulmonary valve using the appropriate exchange guide wire previously introduced into the left pulmonary artery, or into the descending aorta via a persistent ductus arteriosus in two neonates. The lateral image intensifier screen was the prifferred 


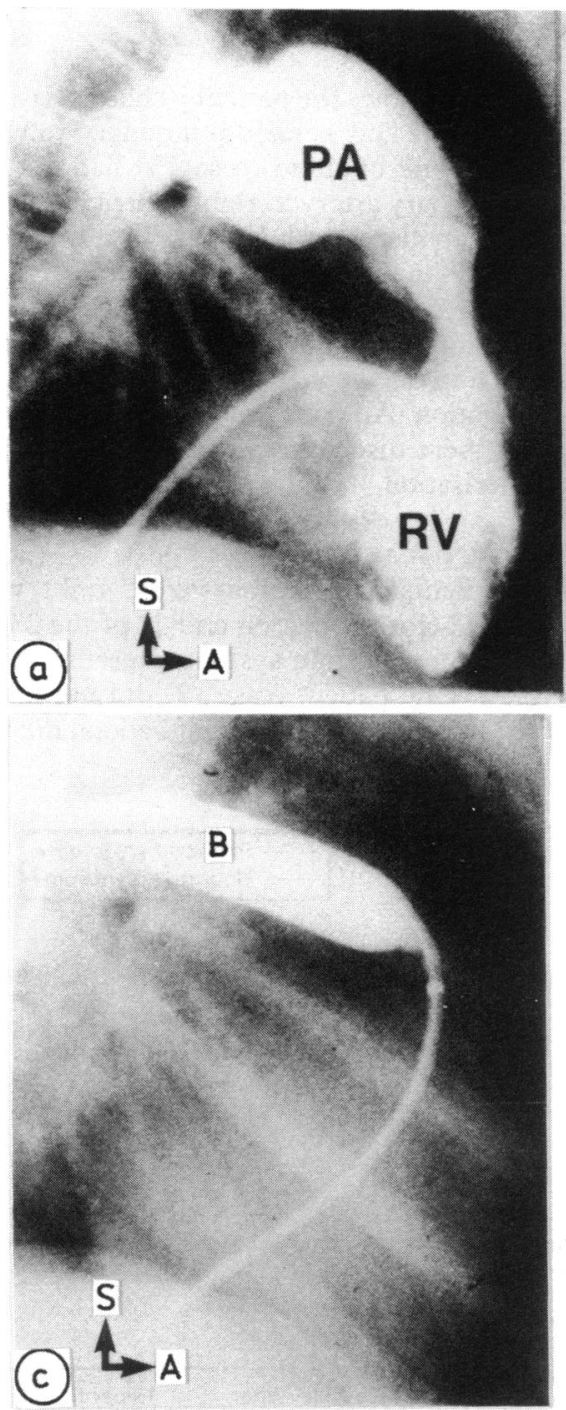

plane for determining satisfactory balloon placement. Rapid balloon inflation with dilute contrast medium was performed by hand, ideally until the indentation in the partially inflated balloon caused by the pulmonary valve leaflets was overcome (Fig. 1). Inflation was maintained for about $10 \mathrm{~s}$, which usually coincided with a rapid decrease in systemic arterial pressure. Sysțemic pressure returned to normal with deflation of the balloon. Balloon inflation was repeated three to five times in each case. The balloon catheter was then re-exchanged for

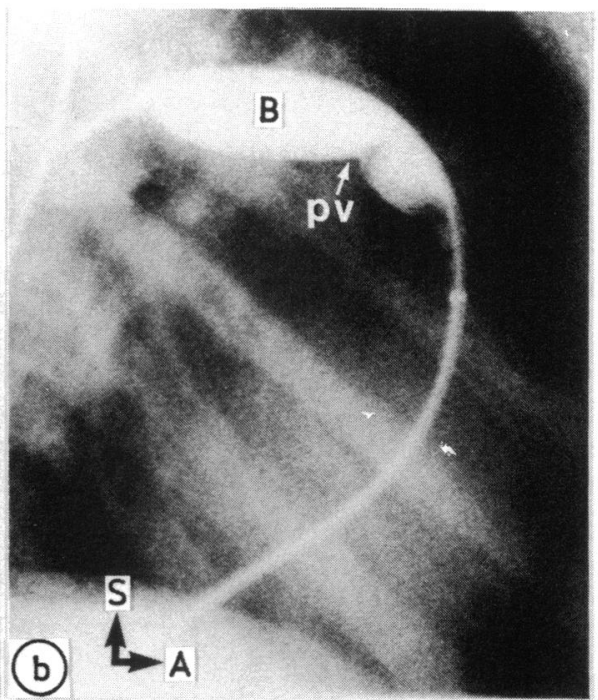

Fig. 1 Lateral right ventricular angiogram in a child with pulmonary stenosis ( $a$ ) before and ( $b$ ) after dilatation and (c) at repeat study. (b) After partial inflation of the balloon indentation by the pulmonary valve leaflets ( $\mathrm{pv}$ ) is present, which disappears after full inflation (c). $P A$, pulmonary artery; $R V$, right ventricle; $B$, balloon; $p v$, pulmonary valve; $A$, anterior; $S$, superior. a Goodale-Lubin catheter for repeat haemodynamic measurements, and right ventricular angiography was also repeated with a suitable catheter.

Repeat cardiac catheterisation has been performed in 12 patients to date. In 11 patients this was an elective repeat study six months after the initial procedure. Repeat balloon dilatation was performed in three of these patients. One neonate with severe pulmonary valve stenosis (case 10) was recatheterised one week after the initial procedure and repeat balloon dilatation performed. 


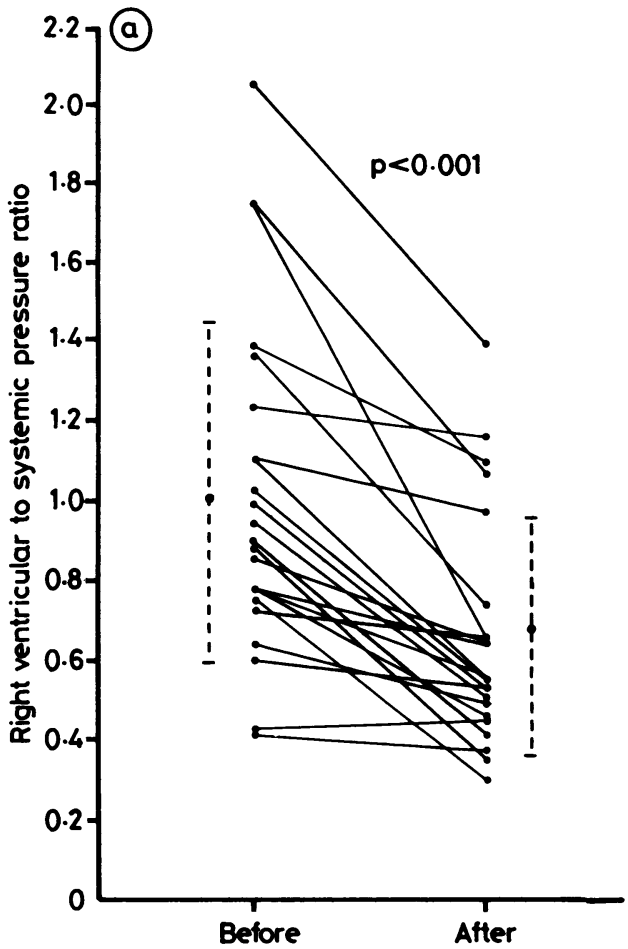

\section{Results}

The Table shows the patients' characteristics. Nineteen patients had isolated pulmonary valve stenosis, although one of these (case 15) had an associated right coronary artery to right ventricle fistula. There were two patients with Noonan's syndrome, and two who had undergone previous surgical valvotomy. The only complication of cardiac catheterisation in these patients was avulsion of the saphenofemoral junction in one neonate, which necessitated femoral vein ligation. All patients, except the three aged $<2$ weeks, were discharged from hospital the day after catheterisation.

\section{INITIAL DILATATION}

Ten patients had suprasystemic right ventricular pressure before dilatation and 21 of the 23 had right ventricle to systemic systolic pressure ratios $>0.6$ (Fig. 2). One patient (case 13) did not have a large pulmonary valve gradient, but balloon dilatation was
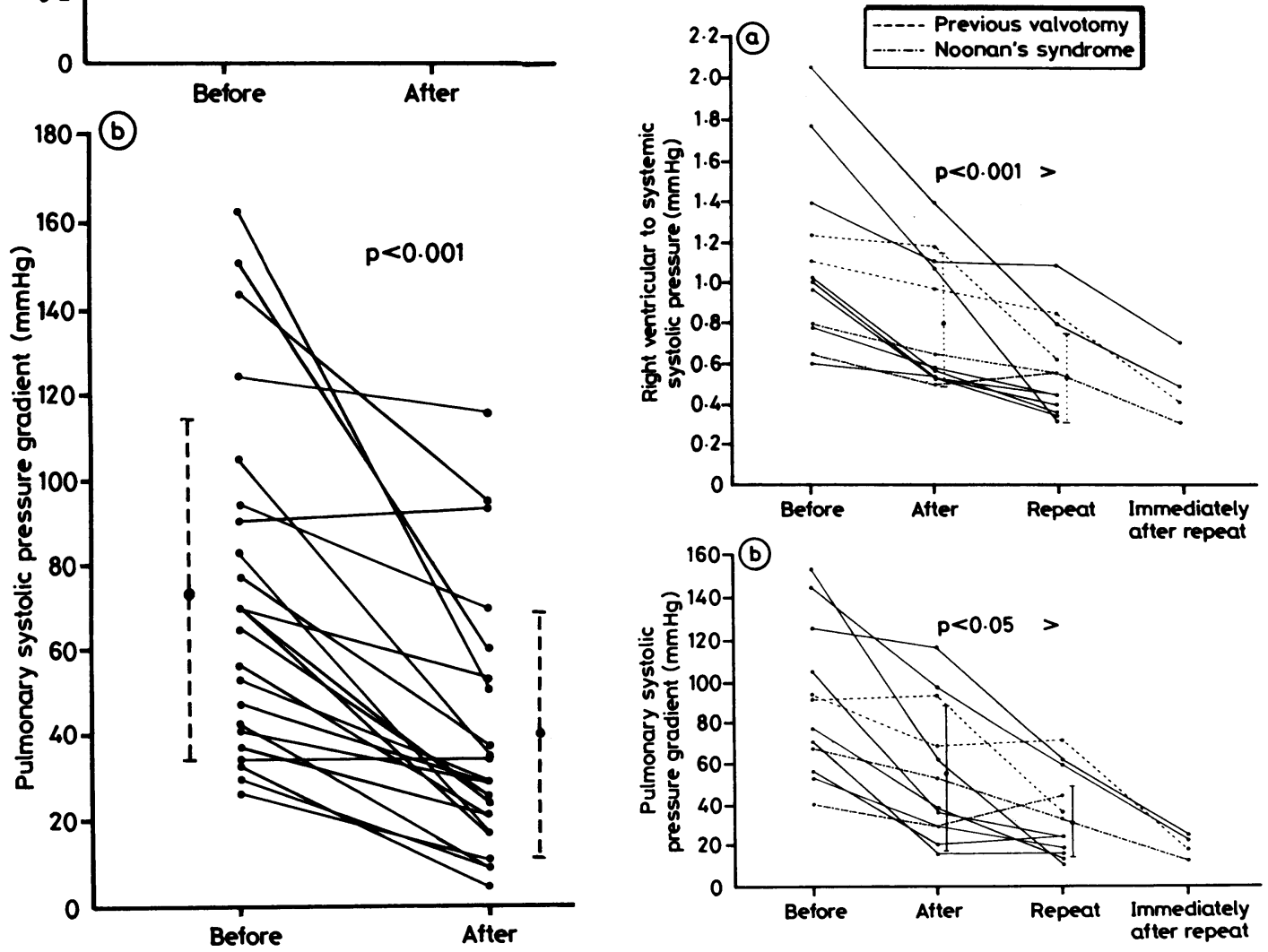

Fig. 2 (a) Right ventricular to systemic systolic pressure ratios and (b) pulmonary systolic pressure gradient befóre and immediately after balloon pulmonary valve dilatation. Bars represent mean (SD).

Fig. 3 (a) Right ventricular to systemic systolic pressure ratios and (b) pulmonary systolic pressure gradients before and immediately after balloon pulmonary valve dilatation and at repeat catheterisation. 


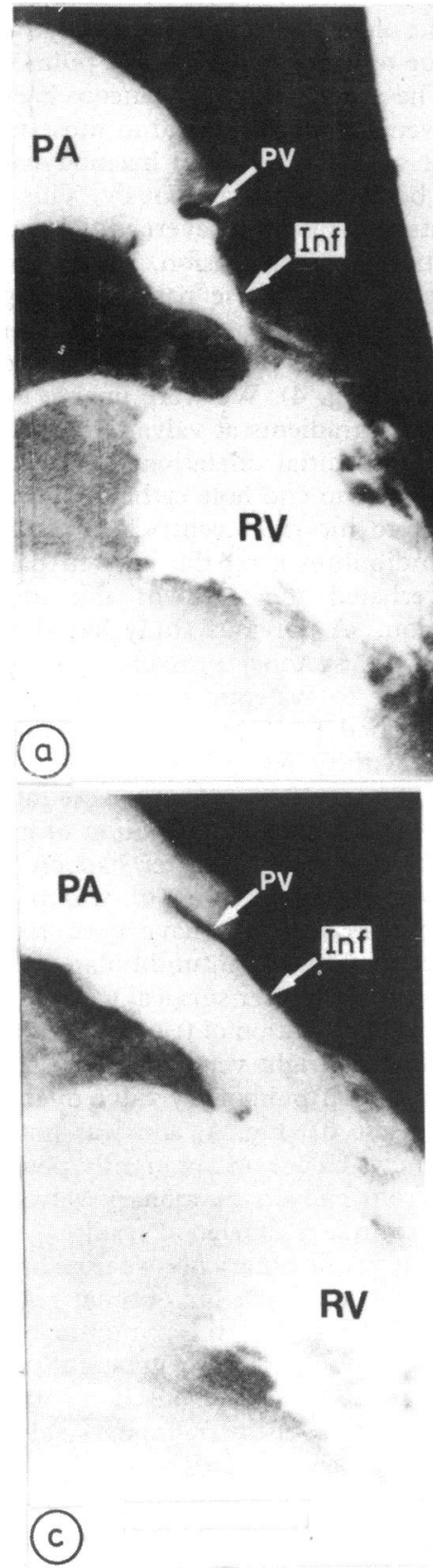

Fig. 4 Right ventricular lateral angiograms (a) before (b) immediately after balloon pulmonary valve $(P V)$ dilatation and $(c)$ at repeat catheterisation, showing regression of infundibular (Inf) stenosis. PA, pulmonary artery; $R V$, right ventricle. performed in an attempt to reduce the moderate tricuspid regurgitation that was present.

Balloon pulmonary valve dilatation resulted in significant immediate haemodynamic improvement. Mean (SD) right ventricular to systemic systolic pressure ratios and peak to peak pulmonary systolic pressure gradients were $1.02(0.42)$ and $76(41) \mathrm{mm}$
$\mathrm{Hg}$ respectively before dilatation compared with $0.67(0.29)(\mathrm{p}<0.001)$ and $39(31) \mathrm{mm} \mathrm{Hg}(\mathrm{p}<0.001)$ after balloon dilatation (Fig. 2). Right ventricular systolic pressure remained at or above systemic level on five occasions, however (Fig. 2a), and in four of these patients the residual pulmonary systolic pressure gradient was $>70 \mathrm{~mm} \mathrm{Hg}$ (Fig. 2b). These 
patients (cases $6,8,10,22$, and 23 ) who had had the least satisfactory initial results underwent a repeat study.

\section{LATE RECATHETERISATION}

There was further appreciable haemodynamic improvement in the 12 patients who underwent repeat study (Fig. 3). Right ventricular to systemic systolic pressure ratios and pulmonary systolic pressure gradients for this group were $0.8(0.32)$ and $56(33) \mathrm{mm}$ $\mathrm{Hg}$ respectively immediately after dilatation, compared with $0.58(0.23)(\mathrm{p}<0.01)$ and $36(20) \mathrm{mm} \mathrm{Hg}$ $(p<0.05)$ at repeat study. This further improvement was modest in patients who had the lowest right ventricular pressures and residual gradients after the initial balloon dilatation procedure. More notable, however, was the major improvement with time that had occurred in the patients who had had less satisfactory initial results (Fig. 3). Four patients with high residual pulmonary gradients and right ventricular systolic pressures underwent successful repeat dilatation, in each case with a bigger balloon than on the first occasion (Fig. 3). Repeat dilatation could not be achieved in one patient (case 22) whose right ventricular pressure remained at $63 \%$ of systemic pressure because the balloon catheter could not be advanced through a left axillary cut down. This patient had undergone surgical valvotomy with a modified Blalock-Taussig shunt on the first day of life for pulmonary atresia with intact ventricular septum. He had a severely dysplastic valve. Although there was no immediate improvement after balloon dilatation, a major improvement did occur six months later. The only other patient with a residual gradient in excess of $26 \mathrm{~mm} \mathrm{Hg}$ (case 20) or right ventricular pressure more than half systemic pressure was a child with Noonan's syndrome and multiple handicaps. In view of the latter and the lack of benefit from the initial dilatation in a child with moderate stenosis only, we elected not to perform repeat balloon dilatation.

\section{Discussion}

Our results confirm earlier reports that balloon dilatation of the pulmonary valve may provide effective relief of pulmonary valve stenosis. Moreover, this is not confined to pulmonary valve stenosis of mild or moderate severity since almost half of the patients in this series had suprasystemic right ventricular pressures. Previous reports of balloon dilatation for pulmonary valve stenosis of similar severity included older patients (age range from 11 months to 19 years), with the most severe lesions occurring mainly in the older patients, ${ }^{34}$ but we have applied the technique to infants with critical pulmonary stenosis.

The pronounced spontaneous haemodynamic improvement that we noted in those patients with the least satisfactory initial haemodynamic results has not been reported previously. This occurred in patients with the most severe initial gradients and right ventricular hypertension. The pronounced residual obstruction in these patients was probably at infundibular level, the subsequent improvement being associated with regression of right ventricular hypertrophy (Fig. 4). We were unable to show separate residual gradients at valvar and infundibular levels after the initial dilatation, however, despite withdrawal of an end hole catheter from the pulmonary trunk to the right ventricle. Direct trauma to the infundibulum from the inflated balloon may have exacerbated the gradient immediately after dilatation. ${ }^{7} \mathrm{~A}$ previous study has shown that reductions in systolic pressure gradients and right ventricle to systemic systolic pressure ratios were maintained, but not further improved, in nine patients with typical pulmonary valve stenosis studied again two to 12 months after the initial procedure. ${ }^{2}$ Two single cases of resolution of mild residual infundibular gradients after balloon pulmonary valvotomy in adults (one of whom had only mild pulmonary stenosis) have been reported. ${ }^{89}$ Analogous resolution of infundibular obstruction has also been reported after surgical pulmonary valvotomy. ${ }^{6}$ The administration of $0.1 \mathrm{mg} / \mathrm{kg}$ of propranolol had no effect on right ventricular pressure immediately after balloon pulmonary valve dilatation in one patient (case 6) (Fig. 4) and was not therefore used routinely. Hence an apparently poor immediate result from balloon pulmonary valve dilatation does not preclude a later good result.

Early in our experience we used balloons that were probably too small for optimal results. Studies in lambs suggest that the optimum balloon diameter should be about $20-30 \%$ greater than the pulmonary valve ring diameter, ${ }^{7}$ but if the balloon diameter exceeds $150 \%$ of the pulmonary valve ring diameter severe damage to the right ventricular outflow tract, particularly the infundibulum, can occur. Support for this is provided by the effectiveness of repeat dilatation in the four patients in whom a larger balloon was used. None of the patients whom we studied again had a diastolic murmur to suggest pulmonary incompetence.

There was a higher proportion of infants in this series than in previous studies, although our technical failures occurred in neonates and small infants. This resulted partly from the relatively large size of the catheter required to carry the appropriate sized balloon in these small patients. This contributed to 
avulsion of the saphenofemoral junction in one neonate, the only complication of the procedure encountered. Balloon length and stiffness of the catheter tip also made manipulation difficult in neonates. $\mathrm{Al}$ though catheter design is likely to improve, the technical problems of entering the pulmonary artery with these large stiff catheters may not allow all symptomatic neonates with severe pulmonary valve stenosis to be improved without surgery.

Poor results from balloon dilatation of pulmonary valve stenosis in patients with dysplasia of the pulmonary valve or previous neonatal surgical valvotomy have been reported. ${ }^{2}$ We had a similarly unsatisfactory result in one patient with Noonan's syndrome, although, in retrospect, the balloon used was probably too small. There was a good result (after two dilatation procedures), however, in another patient with Noonan's syndrome. As patients with dysplastic pulmonary valves are unlikely to form a homogeneous group, this suggests that percutaneous balloon dilatation may still be the initial treatment of choice. We have no means yet of identifying patients with optimal pulmonary valve anatomy. Both children in this series with severe residual pulmonary stenosis after surgical valvotomy (performed at 1 day and 6 months of age respectively) had major haemodynamic improvement with balloon valvuloplasty, albeit after two dilatation procedures in one child. Previous surgical valvotomy is not, therefore, a contraindication for this technique. Stretching of fibrous tissue at the pulmonary valve ring may have contributed to this improvement. This may be analogous to successful balloon dilatation of postoperative residual coarctation of the aorta. ${ }^{10}$

Balloon pulmonary valvuloplasty did not abolish the systolic pressure gradient in any of our patients, although these results are at least similar to those after surgery, where about $20 \%$ of infants and children studied again postoperatively had a residual gradient $>25 \mathrm{~mm} \mathrm{Hg} .{ }^{11}$ The same study showed that pulmonary systolic pressure gradients of $<30$ $\mathrm{mm} \mathrm{Hg}$ were unlikely to increase, whether they occurred in patients managed medically or in those with a residual gradient after surgery. ${ }^{11}$ Residual gradients after balloon pulmonary valvuloplasty therefore, will probably behave similarly, although this remains to be proved:

\section{Addendum}

Since this paper was prepared further studies on this subject have been published. ${ }^{1213}$

\section{References}

1 Kan JS, White RI Jr, Mitchell SE, Gardner TJ. Percutaneous balloon valvuloplasty: a new method for treating congenital pulmonary valve stenosis. $N$ Engl f Med 1982; 307: 540-2.

2 Kan JS, White RI Jr, Mitchell SE, Anderson JH, Gardner TJ. Percutaneous transluminal balloon valvuloplasty for pulmonary valve stenosis. Circulation 1984; 69: 554-60.

3 Lababidi S, Wu J-R. Percutaneous balloon pulmonary valvuloplasty. Am f Cardiol 1983; 52: 560-2.

4 Rocchini AP, Kveselis DA, Crowley D, Dick M, Rosenthal A. Percutaneous : balloon valvuloplasty for treatment of congenital pulmonary valvular stenosis in children. $f$ Am Coll Cardiol 1984; 3: 1005-12.

5 Tynan M, Jones O, Joseph MC, Deverall PB, Yates AK. Relief of pulmonary valve stenosis in first week of life by percutaneous balloon valvuloplasty [Letter]. Lancet 1984; i: 273.

6 Griffith BP, Hardesty RL, Siewers RD, Lerberg DB, Ferson PF, Bahnson HT. Pulmonary valvulotomy alone for pulmonary stenosis: results in children with and without muscular infundibular hypertrophy. $\mathcal{f}$ Thorac Cardiovasc Surg 1982; 83: 577-83.

7 Ring JC, Kulik TJ, Burke.BA, Lock JE. Morphologic changes induced by dilatation of the pulmonary valve anulus with overlarge balloons in normal newborn. lambs. Am $\mathcal{f}$ Cardiol 1985; 55: 210-4.

8 Pepine CJ, Gessner IH, Feldman RL. Percutaneous balloon valvuloplasty for pulmonic valve stenosis in the adult. $\mathrm{Am}$ f Cardiol 1982; 50: 1442-5.

9 Shuck JW, McCormick DJ, Cohen IS, Oetgen .WJ, Brinker JA. Percutaneous balloon valvuloplasty of the pulmonary valve: role of right to left shunting through a patent foramen .ovale. $\mathcal{\exists} \mathrm{Am}$ Coll Cardiol 1984; 4: 132-5.

10 Kan JS, White RI Jr, Mitchell SE, Farmlett EJ; Donahoo JS, Gardner TJ. Treatment of restenosis of coarctation by percutaneous transluminal angioplasty. Circulation 1983; 68: 1087-94.

11 Nugent EW. Freedom RM, Nora JJ, Ellison RC; Rowe RD, Nadas AS. Clinical course in pulmonary stenosis. Circulation 1977; 56: (suppl I): 38-47.

12 Miller GAH. Balloon valvuloplasty and angioplasty in congenital heart disease. $\mathrm{Br}$ Heart $\mathcal{F}$ 1985; 54: 285-9.

13 Tynan M, Baker EJ, Rohmer J, et al. Percutaneous balloon pulmonary valvuloplasty. $\mathrm{Br}$ Heart $\mathcal{F}$ 1985; 53: 520-4. 